\title{
Statistical characteristics of sources of vehicle kinematic excitation
}

\author{
Jozef Melcer ${ }^{1}$, Eva Merčiaková ${ }^{1, *}$ and Mária Kúdelčíková ${ }^{1}$ \\ ${ }^{1}$ University of Žilina, Faculty of Civil Engineering, Univerzitná 8215/1, 01026 Žilina, Slovak \\ Republic
}

\begin{abstract}
The longitudinal and transverse road profiles represent the functions of a random variable from a mathematical point of view. It is appropriate to use methods of probability theory and mathematical statistics for their description. The unevenness of the runway surface is the main source of the vehicle's kinematic excitation. This paper describes the statistical properties of the mapped road profiles. It shows a way of categorizing road surface quality based on the power spectral density of unevenness. The interrelationships between the individual points of the profile and the profiles with one another are evaluated by correlation functions.
\end{abstract}

\section{Introduction}

The unevenness of the runway surface is the main source of the vehicle's kinematic excitation. Unevenness must first be mapped and then mathematically described. Longitudinal or transverse road profiles represent functions of a random variable from a mathematical point of view [1]. To describe them, it is appropriate to use methods of probability theory and mathematical statistics and to quantify their basic numerical characteristics. The files thus obtained serve as inputs for various numerical simulations of processes of vehicle motion along the roads and the interaction of vehicles with the runway [2]. In numerical simulations, a random profile of the runway surface is often numerically generated to meet certain desired parameters. For the description of the unevenness in the frequency domain, the power spectral densities are used and the interrelationships of the individual profiles are evaluated by correlation functions. Applications in practice are different [3-8].

\section{Mapping of stochastic road profile}

Precise leveling was used to map the longitudinal profiles of the runway surface. Leica NA 2002 was used as a leveling instrument, Fig. 1. This instrument uses digital electronic image processing to determine heights and distances and automatically records the results to a REC module that can be transported to a computer. It ensures the elimination of the human factor in reading and processing the measured data.

* Corresponding author: eva.merciakova@fstav.uniza.sk 


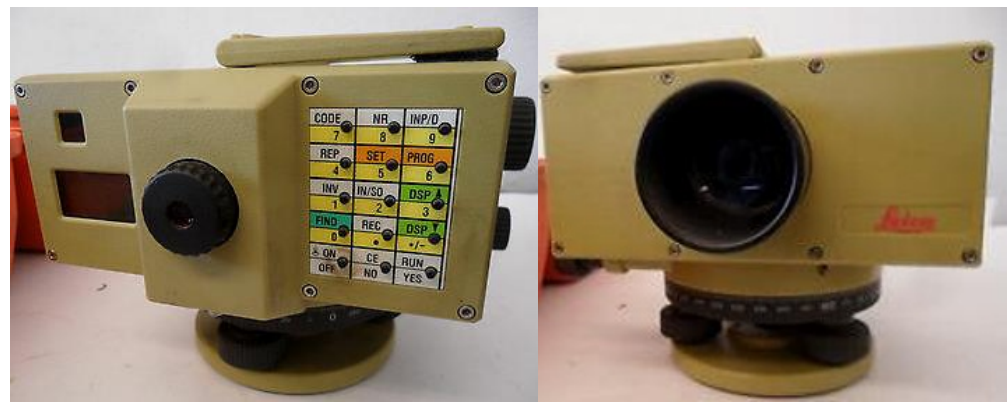

Fig. 1. Leveling instrument Leica NA 2002 [9].

Measurements were performed on two longitudinal profiles, labeled L (left) and R (right). The distance between the measured profiles was $2 \mathrm{~m}$. The leveling points were $0.25 \mathrm{~m}$ longitudinally apart. The measured section was $500 \mathrm{~m}$ long. For a detailed analysis of the profiles, a section with a length of $140 \mathrm{~m}$ was selected, between points with the stationing of $280 \mathrm{~m}$ to 420 m, Fig. 2.
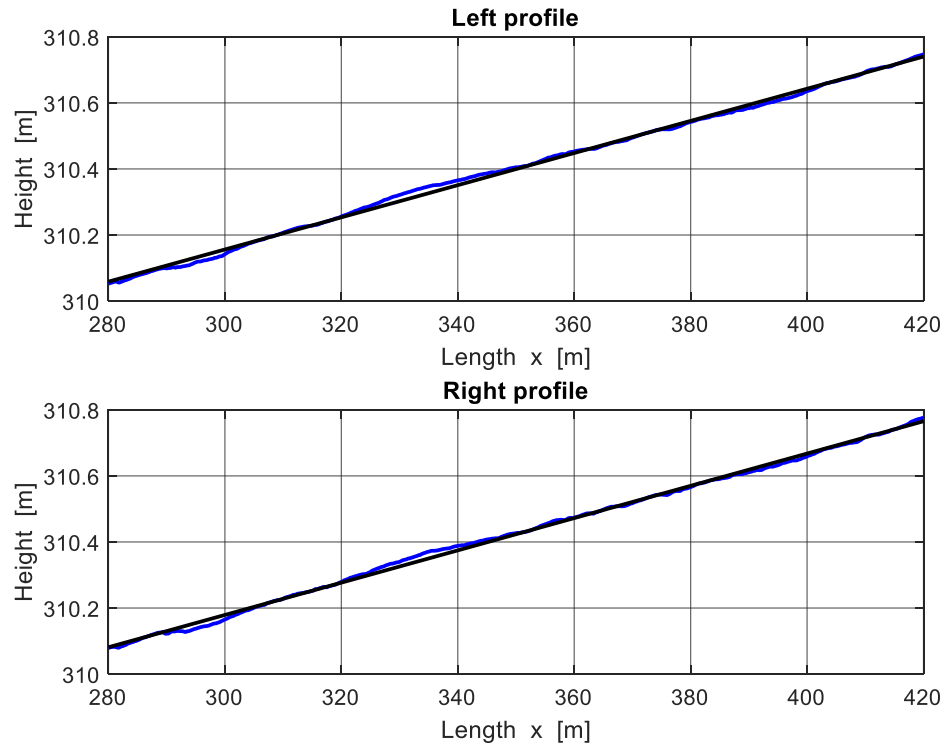

Fig. 2. Selected sections of the Left and Right road profile.

The profiles have approximately the same slope. The slope of the left profile $0.4866 \%$ and the slope of the right profile is $0.4885 \%$. Straightened profiles are shown in Fig. 3.

\section{Basic statistical characteristic of the road profiles}

For further statistical analysis, each record was re-sampled to contain $N=2^{14}=16384$ samples. A cubic spline approximation was used to calculate the intermediate values. All other analyses were performed from these re-sampled files. The basic statistical characteristics for left $(u l)$ and right $(u r)$ road profiles are put into Table 1. 

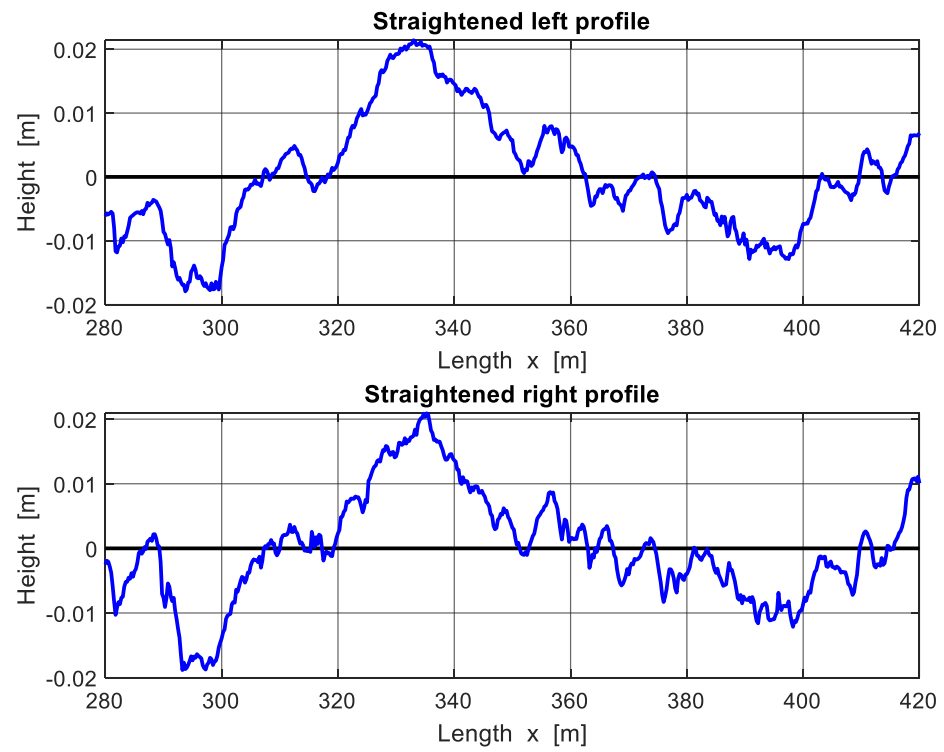

Fig. 3. Straightened Left and Right profiles.

Table 1. Statistical characteristics of road profiles $u l$ and $u r$.

\begin{tabular}{|l|c|c|}
\hline & $u l$ & $u r$ \\
\hline Mean value $\bar{u}$ & $-5.78 \mathrm{e}-04 \mathrm{~mm}$ & $-6.13-03 \mathrm{~mm}$ \\
\hline Arithmetic mean deviation $R_{a}$ & $7.222 \mathrm{~mm}$ & $6.363 \mathrm{~mm}$ \\
\hline $\begin{array}{l}\text { Root mean square average } \\
\text { deviation } R_{q}\end{array}$ & $9.230 \mathrm{~mm}$ & $8.347 \mathrm{~mm}$ \\
\hline Dispersion $\sigma^{2}$ & $85.202 \mathrm{~mm}^{2}$ & $69.670 \mathrm{~mm}^{2}$ \\
\hline Effective value $R M S$ & $9.230 \mathrm{~mm}$ & $8.347 \mathrm{~mm}$ \\
\hline Asymmetry coefficient $R_{s k}$ & 0.395 & 0.240 \\
\hline Kurtosis $R_{k u}$ & 2.733 & 3.009 \\
\hline Greatest depth of unevenness & $-17.935 \mathrm{~mm}$ & $-18.831 \mathrm{~mm}$ \\
\hline The largest height of unevenness & $21.409 \mathrm{~mm}$ & $20.905 \mathrm{~mm}$ \\
\hline Overall height of the profile & $39.344 \mathrm{~mm}$ & $39.736 \mathrm{~mm}$ \\
\hline
\end{tabular}

In general, it is claimed that the density distributions of unevenness are governed by the Gaussian law of normal distribution [10]. To assess this, Fig. 4 and 5 compared the histograms of unevenness in the left and right tire traces and the Gaussian law of normal distribution.

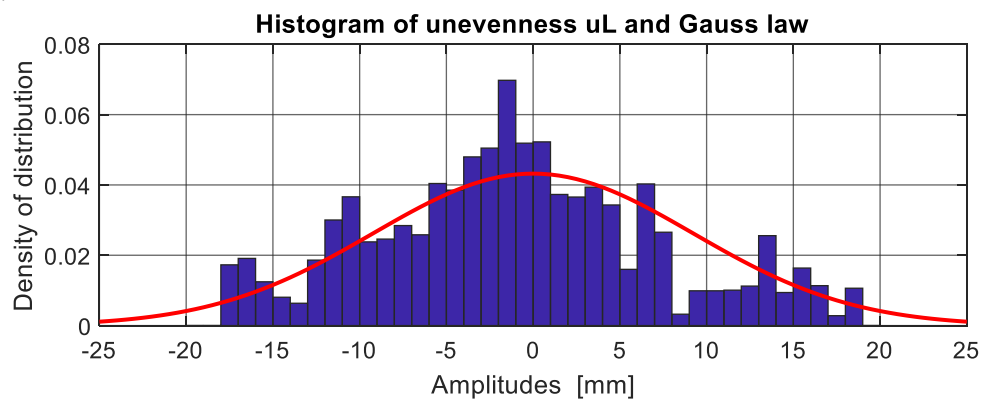

Fig. 4. Histogram of left unevenness and Gaussian law. 


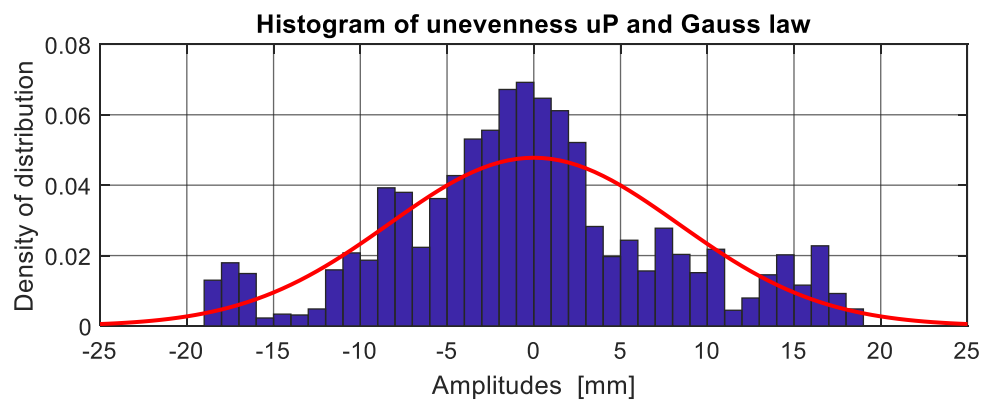

Fig. 5. Histogram of right unevenness and Gaussian law.

\section{Power spectral densities}

The random road profile $u(x)$ is assumed as a stationary ergodic function with zero mean value and normal distribution. The quality of the road surface can be assessed using a number of criteria. In accordance with ISO 8608 [11], the pavements can be classified into eight categories A - H on the basis of Power Spectral Densities, (PSD). The real power spectral densities obtained by processing the measured data can be approximated by the relationship

$$
S_{u}(\Omega)=S_{u}\left(\Omega_{0}\right) \cdot\left(\frac{\Omega}{\Omega_{0}}\right)^{-k}
$$

where $\Omega$ in $[\mathrm{rad} / \mathrm{m}]$ denotes the wavenumber (path circular frequency), $\Omega_{0}=1 \mathrm{rad} / \mathrm{m}$ is the reference wavenumber and the waviness $k=2$. The values of the constant $S_{u}\left(\Omega_{0}\right)$ for the reference wave number $\Omega_{0}=1.0[\mathrm{rad} / \mathrm{m}]$ are shown in Table 2 . Only some limited interval of wavelengths $L$ has a decisive influence on the oscillation of the vehicle. In practice values in the range $L_{\min }=(0.2-0.5) \mathrm{m}$ to $L_{\max }=(50-100) \mathrm{m}$ are considered. These limits are related to the natural frequency of the vehicle and the speed of vehicle movement. If the power spectral density is displayed at a logarithmic scale, the image of the relationship (1) is a line.

Table 2. Classification of road unevenness according to ISO 8608 standard [11].

\begin{tabular}{|c|c|c|c|}
\hline \multirow{2}{*}{ Class } & \multicolumn{3}{|c|}{$S_{u}\left(\Omega_{0}\right)\left[\mathrm{m}^{2} /(\mathrm{rad} / \mathrm{m})\right]$ at $\Omega_{0}=1 \mathrm{rad} / \mathrm{m}$} \\
\cline { 2 - 4 } & lower bound & geometric average & upper bound \\
\hline A & - & $1 \cdot 10^{-6}$ & $2 \cdot 10^{-6}$ \\
\hline B & $2 \cdot 10^{-6}$ & $4 \cdot 10^{-6}$ & $8 \cdot 10^{-6}$ \\
\hline C & $8 \cdot 10^{-6}$ & $16 \cdot 10^{-6}$ & $32 \cdot 10^{-6}$ \\
\hline D & $32 \cdot 10^{-6}$ & $64 \cdot 10^{-6}$ & $128 \cdot 10^{-6}$ \\
\hline E & $128 \cdot 10^{-6}$ & $256 \cdot 10^{-6}$ & $512 \cdot 10^{-6}$ \\
\hline F & $512 \cdot 10^{-6}$ & $1024 \cdot 10^{-6}$ & $2084 \cdot 10^{-6}$ \\
\hline G & $2084 \cdot 10^{-6}$ & $4096 \cdot 10^{-6}$ & $8192 \cdot 10^{-6}$ \\
\hline H & $8192 \cdot 10^{-6}$ & $16384 \cdot 10^{-6}$ & - \\
\hline
\end{tabular}

The power spectral densities calculated for road profiles in Fig. 3 are plotted in log-log scale in Fig. 6. The road profiles can be classified as profiles lying on the border between categories $\mathrm{B}$ and $\mathrm{C}$. 

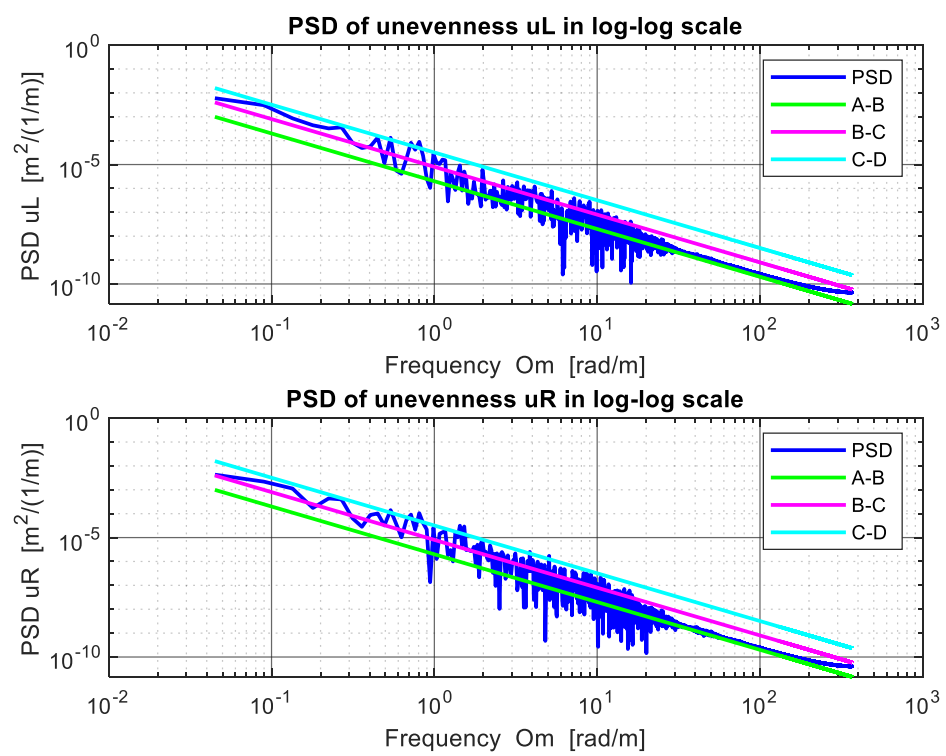

Fig. 6. PSD of left and right profiles in log-log scale.

\section{Correlation functions}

The statistical dependencies between individual points of a random profile, or between two random profiles, describe the correlation functions [12]. The auto-correlation function for one random profile $u(x)$ is described by the relationship

$$
R_{u}(\xi)=\lim _{x \rightarrow \infty} \frac{1}{2 x} \int_{-x}^{+x} u(x) \cdot u(x+\xi) \mathrm{d} x
$$

where $\xi$ is lengthwise displacement in the $X$-axis direction, $\xi=x_{2}-x_{1}$. An important feature of the auto-correlation function is that its zero point value is equal to the dispersion $D_{u}$

$$
R_{u}(0)=D_{u}
$$

This means that the normed auto-correlation function $\rho_{u}(\xi)$ has a function value for $\xi=0$ equals 1

$$
\rho_{u}(0)=\frac{R_{u}(0)}{D_{u}}=1
$$

The normed auto-correlation functions of the left and right road profiles for 16380 numbers of lags are plotted in Fig. 7.

The normed cross-correlation function for two random profiles $u l(x)$ and $u r(x)$ is described by the relationship

$$
R_{u l, u r}(\xi)=\lim _{x \rightarrow \infty} \frac{1}{2 x} \int_{-x}^{+x} u l(x) \cdot u r(x+\xi) \mathrm{d} x
$$

The normed cross-correlation functions of the left and right road profiles for 16380 numbers of lags are plotted in Fig. 8. 

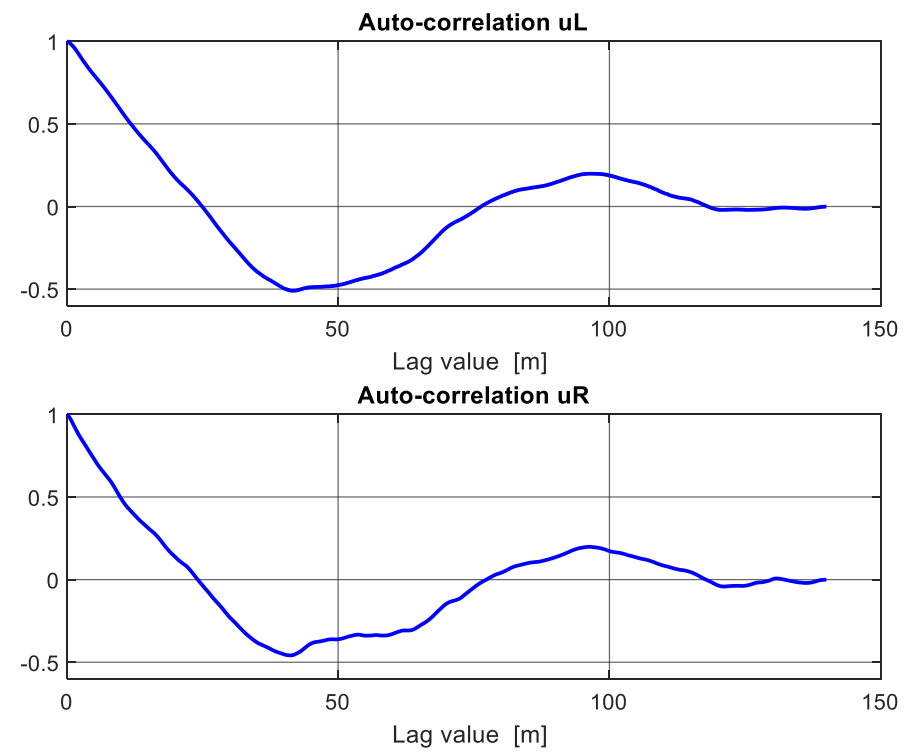

Fig. 7. Normed auto-correlation functions of the left and right road profiles.

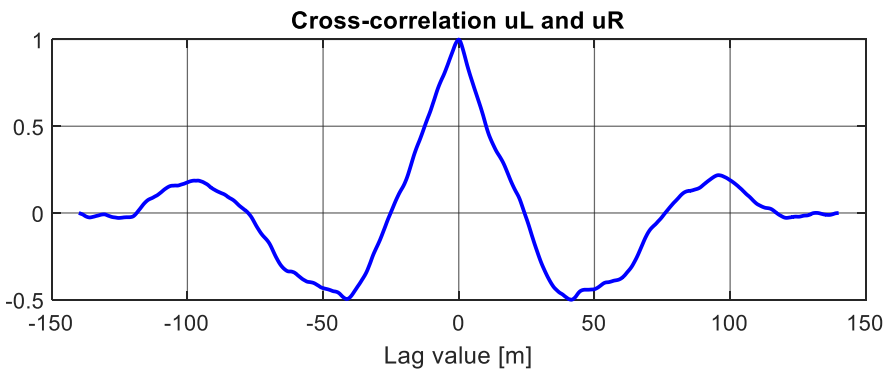

Fig. 8. Normed cross-correlation functions of the left and right road profiles.

\section{Conclusion}

In the solution of the problem of vehicle roadway interaction, the road unevenness represents the main source of kinematical excitation of vehicle. Workers involved in the construction and maintenance of roads map the random profile of the road surface. The quality of the road surface can be assessed using a number of criteria. In accordance with ISO 8608 [11], roadways can be classified into 8 categories $\mathrm{A}-\mathrm{H}$, on the basis of power spectral densities. For numerical simulations of vehicle movement along the road, it is necessary to perform the opposite process than to measure random irregularities on the road. It is necessary to generate a random longitudinal road profile based on the known power spectral density of the unevenness. There is a problem here. During the measurement of random unevenness, only amplitude characteristics are evaluated and the phase characteristics are not evaluated. At the realization of the reverse process one (phase) characteristic is missing. This deficiency is solved by generating a phase shift angle $\varphi_{i}$ as a random number based on a uniform distribution function. By smoothing the power spectral density shown in the log-log scale a line is obtained. It can be very good approximated by equation (1). On the basis of power 
spectral density $S_{u}\left(\Omega_{0}\right)$, for the reference wave number $\Omega_{0}=1.0[\mathrm{rad} / \mathrm{m}]$, the quality of roads surface can be classified into eight categories A $-\mathrm{H}$. But actually on highways and roads of the $1^{\text {st }}$ and $2^{\text {nd }}$ classes, only categories $A \div E$ come into consideration. The statistical dependencies between individual points of a random profile, or between two random profiles, describe the correlation functions. The results of the correlation analysis show that there is little statistical dependence between individual points of the random profile. It is clear to see from the correlation functions that the random profile contains a number of periodically repeating components.

This work was supported by the Grant National Agency VEGA of the Slovak Republic, project number $1 / 0006 / 20$.

\section{References}

1. M. Decký, M. Kováč, Longitudinal unevenness of roads (EDIS, Žilina, in Slovak, 2014)

2. J. Melcer, G. Lajčáková, I. Martinická, J. Králik, Dynamics of Transport Structures (EDIS, Žilina, 2016, in Slovak)

3. E. Panulinová, Silniční obzor, 62, 275-279 (2001)

4. K. Kotrasová, E. Kormaníková, World J. Eng. 5, 445-446, (2008)

5. M. Mikušová, WIT Trans. Built Env. 134, 503-514 (2013)

6. V. Valašková, Dynamic effect of vehicle on the pavement $(\mathrm{PhD}$. Thesis, Univ. of Žilina, 2017, in Slovak)

7. J. Melcer, G. Lajčáková, V. Valašková, Moving load effect on concrete pavements (Wydawnictwo Towarzystwa Slowaków w Polsce, Kraków, 2018)

8. J. Melcer, D. Kuchárová, ICNAAM 2018, New York: AIP Publishing LLC, 2116, (2019)

9. https://picclick.com/Leica-Wild-NA2002-Digital-Level-231545522601.html [4.6.2019]

10. G. Rill, Road vehicle dynamics (London, New York: CRC Press, Taylor \& Francis Group, 2012)

11. ISO 8608, Mechanical vibration - road surface profiles - reporting of measured data. International standard, (1995)

12. J. Prchal, Theory of probability in notification technics (NADAS, Prague, 1975, in Czech) 